\title{
The Priority Analysis of 4PL's Feature Elements in China, Based on Cross-Border E-Commerce from Sellers Perspective
}

\author{
Diyuan $\mathrm{Xu}^{*}$; Yungling Wang; Fengjiao Long \\ Department of International Business \\ Fuzhou Melbourne Polytechnic \\ Fuzhou, China \\ diyuanxu@163.com
}

\begin{abstract}
This paper focuses on how the feature elements of the fourth party logistics are prioritized by the cross-border e-commerce sellers if apply the fourth party logistics to the cross-border e-commerce, as cross-border e-commerce sellers are the demanders and customers of the fourth party logistics. The expert questionnaire and analytic hierarchy process are used as research methods. First, questionnaires are collected from cross-border e-commerce sellers to obtain their scores of the feature elements of the fourth party logistics. Then, the weight of each element is provided by the AHP method to determine its priority. According to this study, Chinese cross-border e-commerce sellers are most concerned about the logistics cost and service of $4 \mathrm{PL}$ when prioritizing the feature elements of 4PL. This study will help to guide the fourth party logistics in the construction path of cross-border logistics, priority build the most urgent functional requirements of customers. In order to achieve the fourth party logistics Step by step in the field of cross-border e-commerce, speed up the closed-loop operation of cross-border e-commerce transactions, as well as bring new motivation to the cross-border e-commerce according to the policy guidance of Belt and Road Initiative and Maritime Silk Road.
\end{abstract}

Keywords-cross-border e-commerce logistics; cross-border e-commerce; the fourth party logistics; priority analysis;

\section{INTRODUCTION}

In recent years, China has further opened up its trade as the Belt and Road Initiative, the maritime Silk Road policy, more and more comprehensive pilot area for cross-border e-commerce, and the Free Trade Area. The cross-border e-commerce obtained the speedy development opportunity in china, however, the cross-border e-commerce was restricted from the logistics. As we all know, nowadays most cross-border e-commerce sells use the third party logistics shipping goods to overseas consumers. But in the perspective of development, the third party logistics has been unable to meet the need for global trade.

The development of fourth party logistics(4PL) is focused by some domestic and foreign scholars, most of them focus on how to achieve one or several features of the fourth party logistics function, the implement, measures and solutions are mostly macroscopic level, there is no scholar focus on the demander of 4PL in the field of cross-border e-commerce. According to public data, at the beginning of 2016, China had more than 200,000 trade companies engaged in cross-border e-commerce [1]. This demonstrates that the demand is huge. For these many of the demand sides, the feature elements of 4PL they need and the priority of the elements would be the guide for the 4PL construction as soon as possible.

Therefore, this study will combine the method of analytic hierarchy process and expert questionnaire, in view of the experts engaged in cross-border trade, quantitative method is used to evaluate the features of the fourth party logistics elements for priority, in order to provide a new perspectives on the realization of the fourth party logistics path, via that the fourth party logistics in the field of cross-border e-commerce could carry on the construction according to the priority of the customers' requirements, quickly realize and create value for the cross-border business and social economy.

\section{OVERVIEW OF CROSS-BORDER E-COMMERCE LOGISTICS AND 4PL}

\section{A. Existing logistics mode of cross-border e-commerce}

At present, China's cross-border e-commerce mainly has five logistics modes, including postal parcel, international express, special line logistics, domestic express and overseas warehouse. However, these five modes all have certain defects [2], as shown in the TABLE I.

TABLE I. CROSS-BORDER E-COMMERCE LOGISTIC MODEL

\begin{tabular}{|c|l|}
\hline $\begin{array}{c}\text { Logistic } \\
\text { Mode }\end{array}$ & \multicolumn{1}{c|}{ Disadvantage } \\
\hline Postal parcel & $\begin{array}{l}\text { Long transport time; } \\
\text { Easy to lose the bag }\end{array}$ \\
\hline $\begin{array}{c}\text { International } \\
\text { express }\end{array}$ & Highest cost \\
\hline $\begin{array}{c}\text { Special line } \\
\text { logistics }\end{array}$ & $\begin{array}{l}\text { Slightly higher cost; } \\
\text { Limited coverage area }\end{array}$ \\
\hline $\begin{array}{c}\text { Domestic } \\
\text { express }\end{array}$ & $\begin{array}{l}\text { Lack of experience in carrying cross-border logistics; } \\
\text { Higher cost ; } \\
\text { Limited coverage area }\end{array}$ \\
\hline $\begin{array}{c}\text { Overseas } \\
\text { warehouse }\end{array}$ & $\begin{array}{l}\text { There are requirements on the nature of goods, and higher } \\
\text { requirements on the inventory control, sales management and } \\
\text { supply chain management ability of the seller, otherwise it is } \\
\text { easy to cause overstock of goods and capital backlog. }\end{array}$ \\
\hline
\end{tabular}


At present, there is no perfect logistics mode with the features of high efficiency, reliability and low price in cross-border e-commerce and the development of cross-border e-commerce is also limited by the logistics bottleneck.[3]

\section{B. Fourth party logistics overview}

The fourth party logistics was first proposed by Accenture in 1996. With the continuous development of cross-border e-commerce in China, the limitations of cross-border logistics have become increasingly prominent, so many domestic scholars have begun to study the optimization and improvement of cross-border e-commerce logistics.

CAI [4] believes that 4PL can optimize the global strategic structure and overall logistics control, and reduce the global logistics cost. Zhao [3] think 4PL and cross-border e-commerce were coupled as a result of the advantage, it will be able to effectively solve the shortage of the cross-border e-commerce logistics, power the important strategy of China's foreign trade transformation and upgrading. The advantage of 4PL has three points, firstly, 4PL has stronger integration and coordination ability than 3PL; secondly the synergy and system optimization mechanism of 4PL can promote the value added of cross-border e-commerce logistics value chain; and finally, 4PL can provide customers with high quality service in the whole supply chain.

Hung [5] studied the key elements of cross-border e-commerce logistics from the perspective of 4PL operators. They found that the comprehensive integration ability of supply chain, technical platform support ability, professional logistics service quality and customer relationship management ability are important ability elements of 4PL suppliers. From the operator's point of view, the customers need by order of capabilities and importance.

From literature found that the 4PL theory was proposed by Accenture. They have been committed to applying the 4PL theory to logistics practice and constantly expanding and improving the theory. Huang [6] made a more comprehensive interpretation about 4PL and conducted a special investigation in key value elements drivers for manufacturers and retailers in selecting fourth party logistics providers. It is significative research from the customer perspective; they sum up the six elements: 4PL supplier's strategy ability and customers cooperate, planning ability and experience, operational efficiency and cost, information integration ability, resources integration ability, service reliability. As these six key elements are proposed to the perspective of customers, the priority study of key elements of 4PL in this paper will be based on this important theoretical basis.

\section{RESEARCH METHODS}

This paper intends to conduct expert questionnaire and hierarchical analysis on the key feature elements of 4PL by Accenture to determine the priority level of the fourth party logistics construction in the cross-border e-commerce environment. So as to provide expert theoretical basis for the development path of 4PL in the cross-border e-commerce.

\section{A. Questionnaire design}

The questionnaire is mainly divided into three parts: 1 ). the first part is the description of each feature element of 4PL and score instructions, which helps experts better understand the questionnaire; 2) The second part is the scoring form, in which the experts compare and score each feature element in pairs; 3) The third part is the personal information of the experts, such as last name, working experience, position.

\section{1) Questionnaire scoring design}

There are 9 levels in total, and experts directly select the scores to compare the importance between two elements. (As TABLE II)

TABLE II. QUESTIONNAIRE SCORE

\begin{tabular}{|c|l|}
\hline Score & \\
\hline 1 & i and $\mathrm{j}$ are equally important \\
\hline 3 & i is slightly more important than $\mathrm{j}$ \\
\hline 5 & i is comparatively more important than $\mathrm{j}$ \\
\hline 7 & i is more important than $\mathrm{j}$ \\
\hline 9 & i is absolutely more important than $\mathrm{j}$ \\
\hline $1 / 3$ & i is slightly less important than $\mathrm{j}$ \\
\hline $1 / 5$ & i is comparatively less important than $\mathrm{j}$ \\
\hline $1 / 7$ & i is less important than $\mathrm{j}$ \\
\hline $1 / 9$ & i is absolutely less important than $\mathrm{j}$ \\
\hline
\end{tabular}

2) Questionnaire index design

This paper establishes the first level of feature elements directly uses the key elements of 4PL proposed by Huang ${ }^{[6]}$. And the second level was built according to the definition of first level elements. (As TABLE III)

TABLE III. QUESTIONNAIRE INDEX

\begin{tabular}{|c|c|c|c|}
\hline \multicolumn{2}{|r|}{ First level feature element } & \multicolumn{2}{|r|}{ Second level feature element } \\
\hline \multirow{2}{*}{ S1 } & \multirow{2}{*}{ Operation efficiency and cost } & S11 & Transport cost \\
\hline & & S12 & Transport speed \\
\hline \multirow{2}{*}{$S 2$} & \multirow{2}{*}{ Service reliability } & S21 & Service response speed \\
\hline & & S22 & Service quality \\
\hline \multirow[b]{2}{*}{ S3 } & \multirow[b]{2}{*}{ Information integration } & S31 & Information system integrity \\
\hline & & S32 & $\begin{array}{l}\text { Providing visual information to } \\
\text { customer }\end{array}$ \\
\hline \multirow{2}{*}{ S4 } & \multirow{2}{*}{$\begin{array}{l}\text { Strategic ability and customers } \\
\text { cooperate }\end{array}$} & $S 41$ & $\begin{array}{l}\text { Responding to corporate } \\
\text { strategy }\end{array}$ \\
\hline & & S42 & $\begin{array}{l}\text { Internal and } \\
\text { collaboration }\end{array}$ \\
\hline \multirow{2}{*}{ S5 } & \multirow{2}{*}{ Resource integration } & S51 & $\begin{array}{lll}\begin{array}{l}\text { Global } \\
\text { network }\end{array} & \text { logistics } & \text { coverage } \\
\end{array}$ \\
\hline & & S52 & $\begin{array}{ll}\begin{array}{l}\text { Global logistics } \\
\text { allocation }\end{array} & \text { resource } \\
\end{array}$ \\
\hline \multirow[b]{2}{*}{ S6 } & \multirow[b]{2}{*}{$\begin{array}{l}\text { Planning } \\
\text { experience }\end{array}$} & S61 & Warehouse layout planning \\
\hline & & S62 & $\begin{array}{l}\text { Operations analysis and } \\
\text { improvement }\end{array}$ \\
\hline
\end{tabular}

The definition of the six feature elements [6] are:

S1: Operation efficiency and cost, efficiency means the speed of logistics, cost means logistics cost.

S2: Service reliability, means 4PL's service capabilities, such as service response speed, quality of service for customers. The communication ability of service personal, risk management ability and the ability to deal with customer complaints will bring the most intuitive feelings to customers.

S3: Information integration capability, refers to use the complete information system to collect and analyze data, more accurate and faster data, enable the supply chain to respond 
faster, more timely and effectively, and provide customers with visual logistics information.

S4: Strategic ability and customers cooperate, means a 4PL provider would understand the company's strategic objectives, participate in the supply chain strategy, cooperate with internal and external customers, and improve the efficiency of enterprise operation and management.

S5: Resource integration, refers to 4PL's ability to reasonably allocate logistics resources and complete logistics and transportation tasks with optimal resource allocation through the logistics network covering the whole world.

S6: Planning ability and experience, means to 4PL must have excellent planning ability of warehouse and logistic design, develop effective transport network optimization program, and through operational analysis and continuous improvement ability, to provide service to customers keeping pace with the times.

\section{B. Questionnaire collection}

In total, 23 expert rating questionnaires were collected, but if the questionnaire options are all 1 ( $\mathrm{i}$ and $\mathrm{j}$ are equally important), that would be regarded as invalid questionnaire, because the 1 is the first options of each question. In the end, there were 19 valid questionnaires. The effective rate of questionnaire collection was $82.6 \%$. Most of the expert are serious about this questionnaire.

\section{Expert profile}

All the experts are from the cross-border e-commerce and International trade industries. There are 7 CEO and operational leaders of cross-border e-commerce companies and the rest were employees.

Among the 19 experts, there are 3 people working for more than 5 years, 3 person working for 3-5 years and others are less than 3 years. As cross-border e-commerce has experienced rapid growth in recent years, the working years are shorter than those in traditional industries.

From the geographical distribution, experts mainly have two regions, Fujian and Zhejiang; Fujian is an important node of the Belt and Road Initiative and the starting point of the maritime Silk Road. Zhejiang is the birthplace of China's e-commerce, but also a considerable export province. Both of these two provinces have a good environment of cross-border e-commerce.

The cross-border e-commerce sellers are the demander, user and customer of 4PL, they have front-line work experience. Based on their understanding of the cross-border logistics industry and their own need, they rank the feature elements of 4PL, which could provide the most valuable advice for the construction of 4PL in the field of cross-border e-commerce.

\section{RESUlT AND DisCUSSION}

Through the AHP software, using the scoring results of the expert questionnaire to construct the weight matrix (As TABLE IV). Here is an example of a CEO of a cross-border e-commerce company.
TABLE IV. QUESTIONNAIRE SCORE MATRIX

\begin{tabular}{|l|c|c|c|c|c|c|}
\hline & $\boldsymbol{S 1}$ & $\boldsymbol{S} 2$ & $\boldsymbol{S 3}$ & $\boldsymbol{S 4}$ & $\boldsymbol{S 5}$ & $\boldsymbol{S 6}$ \\
\hline $\boldsymbol{S} \mathbf{1}$ & 1 & 3 & 5 & 7 & 5 & 7 \\
\hline $\boldsymbol{S} \boldsymbol{2}$ & $1 / 3$ & 1 & 5 & 7 & 7 & 7 \\
\hline $\boldsymbol{S} 3$ & $1 / 5$ & $1 / 5$ & 1 & 5 & 7 & 7 \\
\hline $\boldsymbol{S} 4$ & $1 / 7$ & $1 / 7$ & $1 / 5$ & 1 & 5 & 7 \\
\hline $\boldsymbol{S} 5$ & $1 / 5$ & $1 / 7$ & $1 / 7$ & $1 / 5$ & 1 & 5 \\
\hline $\boldsymbol{S} 6$ & $1 / 7$ & $1 / 7$ & $1 / 7$ & $1 / 7$ & $1 / 5$ & 1 \\
\hline
\end{tabular}

After modified calculation:

$\lambda \max =6.6208 ; \mathrm{CR}=0.0985 ; \mathrm{CI}=0.1242$.

Because of the $\mathrm{CR}<0.1$, The matrix has a satisfactory consistency. (As TABLE V).

TABLE V. MODIFIED MATRIX

\begin{tabular}{|l|c|c|c|c|c|c|c|}
\hline & S1 & S2 & S3 & S4 & S5 & S6 & weight \\
\hline S1 & 1 & 2.2315 & 2.0532 & 6.814 & 5.7991 & 6.9206 & 0.3639 \\
\hline S2 & 0.4481 & 1 & 2.9955 & 5.0312 & 7.3008 & 8.0066 & 0.3002 \\
\hline S3 & 0.4871 & 0.3338 & 1 & 2.5606 & 4.981 & 8.0865 & 0.1773 \\
\hline S4 & 0.1468 & 0.1988 & 0.3905 & 1 & 3.6143 & 6.2846 & 0.0885 \\
\hline S5 & 0.1724 & 0.137 & 0.2008 & 0.2767 & 1 & 4.5944 & 0.0473 \\
\hline S6 & 0.1445 & 0.1249 & 0.1237 & 0.1591 & 0.2177 & 1 & 0.0229 \\
\hline
\end{tabular}

Combine all of the 19 expert modified matrix through geometric average of the corresponding position, the group decision matrix is obtained. Result is shown in Fig. 1.

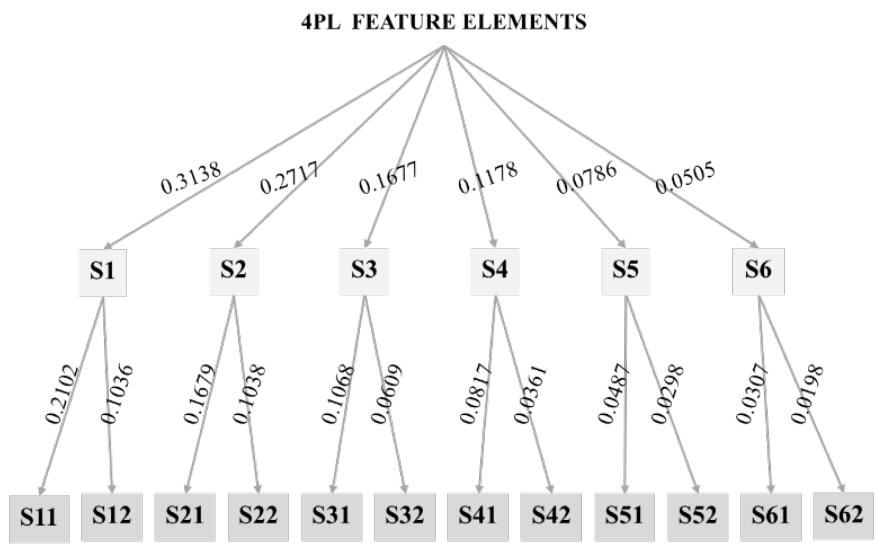

Fig. 1. The weight of $4 \mathrm{pl}$ feature elements

1. From the perspective of cross-border e-commerce sellers the top three priority feature elements in the development of the fourth party logistics are operational efficiency and cost, service reliability and information integration ability.

Most of the experts interviewed in this survey are working for small and medium-sized cross-border e-commerce companies, which are still in the critical period of survival in the early stage of enterprise development. Therefore, they are more sensitive to feature elements related to their company's costs and customer service and have more urgent need.

Depending on the report released from the big data analysis company Yiguan [7] in 2018, more than 85 percent of sellers with sales of $\$ 2.5$ million or less, and just 2.5 percent of big sellers with sales of more than $\$ 10$ million. The annual sales of 
less than 100,000 orders accounted for more than $70 \%$ of the sellers. In terms of sales amount and volume, small sellers still dominate the market. So if the 4PL applied to the cross-border e-commerce field, it is important to provide good service to those small and medium companies.

2. To the cross-border e-commerce sellers, strategic ability and customer cooperate, resource integration ability, planning ability and experience in the fourth party logistics are relatively weak. It doesn't mean that these three elements are not essential, but in terms of the urgency of the demand, relatively weak. In the field of cross-border e-commerce, the construction of 4PL logistics system has lower priority.

3. From a global perspective, in the second level of feature elements, cross-border e-commerce sellers have more urgent need for transport costs, service response speed and service quality. This is also the lack of third-party logistics. Logistics is an extension of cross-border e-commerce services, and the quality of logistics services will directly affect consumers' judgment on the service quality of cross-border e-commerce sellers. Therefore, it can be discovered from this study that China's cross-border e-commerce sellers also have a strong demand for improving logistics services.

4PL connects buyers and sellers, and from the perspective of buyers, comes to a similar priority. A report by Forrester found the top three problems that cross-border buyers pay attention to are that product quality and durability are not as good as described; goods not received; damaged product upon arrival; the latter two are related to cross-border logistics. Both buyers and sellers need better and more reliable logistics services ${ }^{[8]}$

\section{CONCLUSION}

Based on the perspective of cross-border e-commerce sellers, this article uses the method of expert questionnaire and the analytic hierarchy process, give the priority of 4PL's six feature elements proposed by Accenture. It could be found that sellers as the 4PL demanders and customers. They need 4PL to improve the current problems of 3PL such as high cost and service quality. And the priority of $4 \mathrm{PL}$ elements could guide the construction of 4PL in the cross-border e-commerce.
It's hoped that the 4PL could be applied in the logistics service of cross-border e-commerce as soon as possible, so as to address the problems with the current cross-border e-commerce logistics and provide efficient and high-quality logistics service for both buyers and sellers. Under the encouragement of the Belt and Road Initiative and the maritime Silk Road policies, we will vigorously develop cross-border e-commerce, accelerate the global trade rate and motivate the global economy.

\section{REFERENCES}

[1] Ministry Of Commerce Of The People's Republic Of China, "Ministry Of Commerce Of The People's Republic Of China," 2016. (Online). Available: http://www.12312.gov.cn/articlemain/hyjg/dzsw/201611/114778.html. [Accessed March 12, 2019].

[2] L. X. Yu, cross-border e-commerce Theory And Practice, Beijing, Capital Economic And Trade University Press, 2017

[3] G. H. Zhao, "A New Way To Solve The Problem Of cross-border e-commerce Logistics: The Fourth Party Logistics," China Economic And Trade Herald, Vol. 26, Pp. 16-20, 2014. (In Chinese)

[4] W. Z. Cai, "The Development Analysis Of The Fourth Party Logistics Viewed By The Global Transportation System," Journal Of Guanxi Vocational And Technical College, Vol. 4, Pp. 19-21, 2014. (In Chinese)

[5] F. S. Hung And H. H. Tai, "A Study On Critical Feature Elements And Operation Models For Fourth Party Logistics Providers To Develop cross-border e-commerce Logistics In Taiwan”, Maritime Quarterly, Vol. 6, Pp. 25-54, 2017. (In Chinese)

[6] X. M. Huang, Z. J. Wen, L. Quan And J. L. Li, "Forth Party Logistics _"Super Managers" Among Logistics Suppliers,” Zhanwang: New Business, Shanghai, Shanghai Jiao Tong Univeersity Press, 2017. (In Chinese)

[7] Yiguan, "China's 2018 White Paper On The Development Of cross-border e-commerce Exports,” Yiguan, 2019. (Online). Available: https://www.analysys.cn/article/analysis/detail/20019136 [Accessed March 13, 2019].

[8] Forrester Consulting, "Global cross-border e-commerce Marketing White Paper,” Forrester Consulting, 2018. (Online). Available: http://www.sohu.com/a/241165756_100020617 [Accessed March 14, 2019 